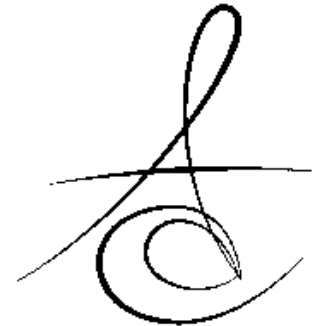

Makale Kodu/Article code: 2425

Makale Gönderilme tarihi: 13.10 .2015

Kabul Tarihi: 12.11 .2015

\section{FARKLI ŞEKİLLERDE YAPILAN MARJİNAL MANDİBULEKTOMİLERİN POSTOPERATİF KIRIK RİSKİ AÇISINDAN SONLU ELEMAN ANALİŻ İLE DEĞERLENDİRİLMESİ ${ }^{\Phi}$}

\section{THE EVALUATION OF DIFFERENT FORMS OF MARGINAL MANDIBULECTOMIES IN TERMS OF POSTOPERATIVE FRACTURE RISK}

Dr. Dt. Recep KESTANE*
Dr. Dt. M. Emre YURTTUTAN**

\section{ÖZET}

Amaç: Çalışmamızın amacı, sonlu eleman analizi yöntemini kullanarak marjinal mandibulektomiler sonrası rezidüel kemikte oluşabilen kırıkları önlemek için ideal bir rezeksiyon tasarımı ortaya çıkarabilmektir. $\mathrm{Bu}$ amaçla sıkça kullanılan iki farklı tip tasarım karşılaştırılmıştır.

Gereç ve yöntem: Tomografi görüntülerinden üç boyutlu olarak elde edilen matematiksel mandibula modelleri üzerinde posterior korpus bölgesinde köşeli ve eğimli olmak üzere iki farklı tip marjinal mandibulektomi uygulanmıştır. Elde edilen bu iki modelde ısırma kuvvetleri altında oluşan stresler sonlu eleman analizi yöntemiyle değerlendirilmiştir.

Bulgular: Modeller; minimum ve maksimum asal gerilimler (minimum ve maksimum principal stres), eşdeğer asal gerilim (Von Mises stres) ve yer değiştirmeler açısından değerlendirilmiş ve karşılaştırmalar yapılmıştır. Her iki modelde de en yüksek stresler defektin postero-inferior köşelerinde oluşmuştur. Benzer şekilde yer değiştirme değerleri de her iki modelde arka köşelerde daha yüksek bulunmuştur. Köşeli modelde tüm bölgelerde eğimli modele kıyasla daha yüksek stresler ve yer değiştirmeler oluştuğu görülmüştür.

Sonuç: Her iki modelin de defektin postero-inferior köşelerinden kırılmaya daha yatkın olduğu ve köşeli modelin de eğimli modele göre daha yüksek postoperatif kırık riski taşıdığı sonucuna varılmıştır.

Anahtar sözcükler: Sonlu eleman analizi, marjinal mandibulektomi, postoperatif kırık

\begin{abstract}
Aim: The purpose of this study is to reveal an optimum marginal mandibulectomy design to prevent postoperative fractures. So then, two different common designs were compared with finite element analysis.
\end{abstract}

Material and methods: Two types of marginal mandibulectomies (angular and curviliniear) were performed on the posterior corpus of a 3 dimensional mathematical mandible model which was created from the tomography images. Stresses which took place on those two models under bite forces, were evaluated with finite element analysis.

Results: The models were evaluated and compared in terms of; minimum and maximum principal stresses, Von Mises stress and displacement magnitude. The highest stresses occured in the postero-inferior corners of the defects on both of the models. Similarly, the highest displacement magnitudes were measured in the posterior corners of both models. Higher stresses and displacement magnitudes were measured in all sites of the angular model compared to curvilinear one.

Conclusion: We conclude that, both of the models' postero-inferior corners were more prone to be fractured and the angular model had more postoperative fracture risk in comparison with the curvilinear one.

Key words: Finite element analysis, marginal mandibulectomy, postoperative fracture

\footnotetext{
Serbest Hekim

** Ankara Üniversitesi Diş Hekimliği Fakültesi Ağız, Diş ve Çene Cerrahisi A.D.

${ }^{\Phi}$ Bu çalışma, Ankara Üniversitesi Sağlık Bilimleri Enstitüsü̈ tarafından 2015 yılında kabul edilen Dr. Dt. Recep KESTANE' ye ait doktora tezinin bir bölümüdü̈r.
} 


\section{GİRIŞ}

Mandibulada çok çeşitli patolojiler ortaya çıkabilmekte ve bu patolojilerin tedavisinde mandibula rezeksiyonları sıklıkla uygulanmaktadır. Patolojinin tipine, yerine ve büyüklüğüne göre segmental mandibulektomiler (mandibula devamlılığının bozulduğu olgular) veya marjinal mandibulektomiler (mandibula devamlılığının bozulmadığı olgular) tercih edilebilmektedir. ${ }^{1,2}$

Marjinal mandibulektomi $\mathrm{Cril}^{3}$ tarafından "mandibula alt kısmındaki kemiği koruyarak keskin bir keski veya testere yardımıyla kemiğin bir parçasının, alveolün üzerindeki tümöral dokuyla birlikte rezeke edilmesi" şeklinde tanımlanmıştır.

Marjinal mandibulektominin güncel tanımı ise; mandibula alt kenarındaki kemiğin korunarak, mandibular alveoler kemiğin lingual kısmının veya hem bukkal hem de lingual kısmın tamamının rezeksiyonu şeklindedir. ${ }^{4}$

Yöntem, alt çenede veya ağız tabanında görülen malign ve lokal agresif olan tümörlerin eksizyonunda başarı ile uygulanmaktadır. Mandibula alt kenarını koruyarak tümörün cerrahi sınırlarını tamamen içine alacak boyutlarda hazırlanan, iki vertikal ve bir horizontal osteotomiden oluşan konservatif bir tekniktir.

Tekniğin avantajları; hasta için konfor artışı, postoperatif fonksiyon kaybının az olması, daha hızlı iyileşme, maliyetin azalması ve uygulanan işlemin hasta ve hekim açısından daha kolay olması, estetik ve hasta kabulunun iyi olması, rekonstrüksiyon ve rehabilitasyonun daha iyi sağlanabilmesidir. Ancak bu avantajların yanında, marjinal rezeksiyon sonrası rezidüel mandibulanın yapısının zayıflaması, postoperatif dönemde mandibulada patolojik kırık oluşma ihtimalini doğurmaktadır. ${ }^{5}$

Çalışmamızın amacı, sonlu eleman analizi yöntemini kullanarak marjinal mandibulektomiler sonrası rezidüel kemikte oluşabilen kırıkları önlemek için ideal bir rezeksiyon tasarımı ortaya çıkarabilmektir. Bu amaçla sıkça kullanılan iki farklı tip tasarım karşılaştııımıştır.

\section{GEREÇ VE YÖNTEM}

Üç boyutlu sonlu elemanlar stres analizinin bilgisayarda çözümü için katı modelleme (solid modelling), ağ yapısının oluşturulması (mesh generation), eleman ve düğüm noktalarının belirlenmesi (elements and nodes), sınır koşullarının tayini (boundary conditions), modelin çözümü (model solution), analizlerin gösterimi (postprocessing) aşamaları takip edilmiştir.

3 boyutlu ağ yapısının düzenlenmesi ve daha homojen hale getirilmesi, 3 boyutlu katı modelin oluşturulması ve sonlu elemanlar stres analizi işlemi için Intel Xeon ${ }^{\circledR} \mathrm{R}$ CPU 3,30 GHz işlemci, 500gb Hard disk, 14 GB RAM donanımlı ve Windows 7 Ultimate Version Service Pack 1 işletim sistemi olan bilgisayardan, Rhinoceros 4.0 (3670 Woodland Park Ave N,Seattle, WA 98103 USA) 3 boyutlu modelleme yazılımından ve Algor Fempro (ALGOR, Inc. 150 Beta Drive Pittsburgh, PA 15238-2932 USA) analiz programından yararlanılmıştır.

Kemik dokularının modellenmesi için, bir hastaya ait daha önce çekilmiş tomografi görüntüleri 3ddoctor yazııımına atılmış ve burada "Interactive Segmentation" yöntemi ile Hounsfield değerlerine bakılarak kemik dokusu ayrıştırılmıştır. Yapılan ayrıştırma işleminden sonra "3d Complex Render" yöntemi ile 3 boyutlu model elde edilmiş ve bu şekilde kemik dokusu modellenmiştir. Daha sonra kemik dokusundan offset yöntemi ile spongioz kemik elde edilmiştir.

Elde edilen kemik dokular Vr-Mesh yazılımı ile sol posterior korpus bölgesinde antero-posterior yönde $3 \mathrm{~cm}$ boyunda ve kesinin altında eşit kalınlıkta rezidüel kemik kalacak şekilde köşeli ve eğimli olmak üzere iki farklı mandibulektomi yapılarak iki ayrı model elde edilmiştir.

Bu şekilde mandibuler kortikal ve spongioz kemikler gerçek morfolojisini yansıtacak biçimde modele taşınmıştır. Yapılan modellemeler Rhinoceros yazııımında, 3 boyutlu uzayda doğru koordinatlara yerleştirilmiş ve modelleme işlemi tamamlanmıştır.

Haritalama ve serbest yöntem olmak üzere iki tip ağ yapı oluşturma yöntemi vardır. Çalışmamızda, istenilen hacimde elemanlar oluşturulabilen serbest yöntem kullanılmıştır.

Rhino'da yapılan modellemeler, 3 boyutlu koordinatlar korunarak Fempro yazılımına aktarılmıştır. Burada modeller Bricks ve Tetrahedra elemanlar şeklinde katı modele çevrilmiştir.

Modeller lineer, homojen ve izotropik materyaller olarak kabul edilmiştir. Çalışmamızda kullanılan modellere ait eleman ve düğüm sayıları Tablo 1' de, kullanılan materyallerin mekanik özellikleri ise Tablo 2' de belirtilmiştir. ${ }^{6}$ 
Tablo 1. Elde edilen modellere ait eleman ve düğüm sayılar

\begin{tabular}{|l|l|l|}
\hline & Eleman SayıSı & Düğüm (Node) SayıSı \\
\hline Köşeli Model & 183356 & 47834 \\
\hline Eğimli Model & 192184 & 49766 \\
\hline
\end{tabular}

Tablo 2. Modellerde kullanılan materyallerin mekanik özellikleri

\begin{tabular}{|l|l|l|}
\hline & Young's Modulu & Poisson Oranı \\
\hline Spongioz Kemik & 1500 & 0,3 \\
\hline Kortikal Kemik & 14000 & 0,3 \\
\hline
\end{tabular}

Modeller dişlerin kuronlarının üst yüzeyinden her DOF (Degree of freedom)'da sıfır harekete sahip olacak şekilde sabitlenmiştir. Kondil bölgesinde ise sadece $\mathrm{x}$ ekseninde rotasyona izin verecek şekilde sabitleme yapılmıştır.

Çeneyi kapatan çiğneme kaslarının ısırma sırasında çeneye uyguladıkları kuvvetler Tablo 3' te gösterilmiştir. Bu kuvvetler kasların mandibulaya tutunma bölgelerinden ve kas çekme doğrultuları göz önünde bulundurularak uygulanmıştır. ${ }^{7-11}$

Tablo 3. Çeneyi kapatan kaslar ve ısırma sırasında uyguladıkları kuvvetler

\begin{tabular}{|l|l|}
\hline Kaslar & Kuvvetler (N) \\
\hline Yüzeyel Masseter & 190,4 \\
\hline Derin Masseter & 81,6 \\
\hline Medial Pterygoid & 174,8 \\
\hline Anterior Temporalis & 158,0 \\
\hline Orta Temporalis & 95,6 \\
\hline Posterior Temporalis & 75,6 \\
\hline
\end{tabular}

\section{BULGULAR}

Köşeli ve eğimli kemik kesisi yapılarak oluşturulan iki adet model; minimum ve maksimum asal gerilimler (minimum ve maksimum principal stres), eşdeğer asal gerilim (Von Mises stres) ve yer değiştirmeler açısından değerlendirilmiş ve karşılaştırmalar yapılmıştır. Gerilim değerleri kortikal ve spongioz kemikte ayrı ayrı olmak üzere, genellikle stres birikimlerinin fazla olduğu köşe noktalardan alınmış ve modeldeki en yüksek stres değeri de ayrıca kaydedilmiştir. Yer değiştirme değerleri de mandibulektomi bölgesinin ön üst, ön alt, arka alt ve arka üst bölgelerinde ayrı ayrı ölçülmüştür.

Sonuçlarda elde edilen üç boyutlu görüntülerde her renk bir değer aralığını tanımlamaktadır. Görüntülerin yan tarafındaki skala ile değer aralıkları gösterilmektedir. Modeller üzerinde renkler stres yoğunlukları ile doğru orantılı olarak değişmektedir.

Maksimum asal gerilim (Principal Stress Max) ve eşdeğer asal gerilim (Von Mises Stress) değerleri pozitif değerlerdir. Sadece sıkışma stres değeri yani minimum asal gerilim (principal stres min) negatif olarak ifade edilir. Bu değerlerin büyüklüğü mutlak değer kabul edilerek karşılaştırılmalıdır.

Köşeli ve eğimli modellerde ısırma kuvvetleri altında meydana gelen Von Mises stres değerlerinin dağılımları değerlendirildiğinde (Şekil 1), streslerin daha çok defektin arka bölgelerinde toplandığı ve köşeli modelden bütün bölgelerde daha yüksek stres değerleri alındığı gözlenmiştir (Şekil 2).
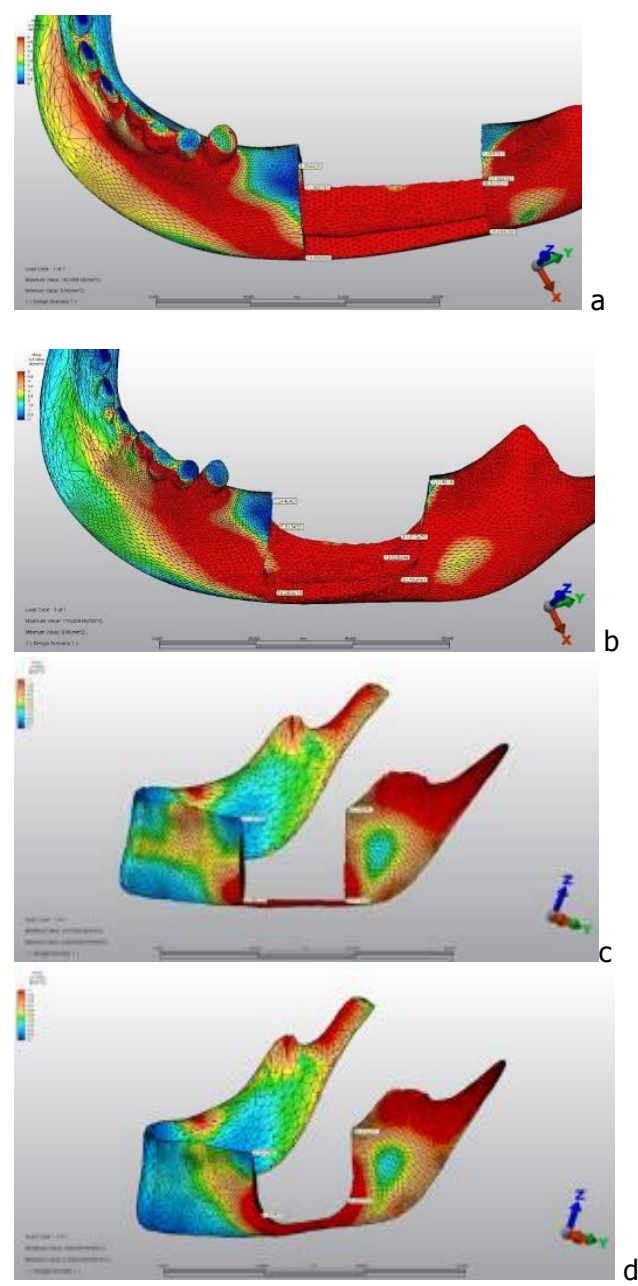

Şekil 1. a) Köşeli modelin kortikal kemiğinde oluşan Von Mises stres değerlerinin dağılımı b) Eğimli modelin kortikal kemiğinde oluşan Von Mises stres değerlerinin dağılım. c) Köşeli modelin spongioz kemiğinde oluşan Von Mises stres değerlerinin dağılımı. d) Eğimli modelin spongioz kemiğinde oluşan Von Mises stres değerlerinin dağılımı

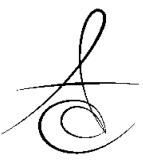




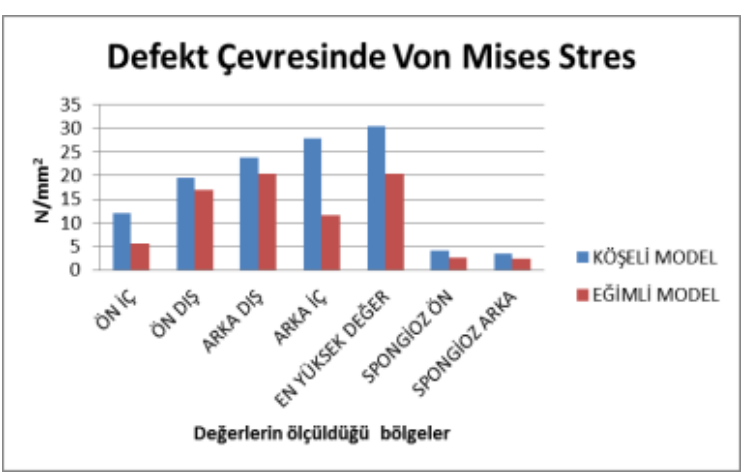

Şekil 2. Köşeli ve eğimli modellerde oluşan Von Mises stres değerlerinin karşılaştırılması

Köşeli ve eğimli modellerin kortikal ve spongioz kemiklerinde oluşan maksimum principal stres değerlerinin dağılımlarına bakıldığında (Şekil 3) ise, her bir model için defektin arka köşelerindeki streslerin ön köşelere oranla çok daha fazla olduğu görülmüştür. Köşeli modelde streslerin en fazla biriktiği bölge defektin arka iç köşesi iken, eğimli modelde arka dış köşede stresler daha fazla yoğunlaşmıştır. Köşeli modelde ölçülen değerler bütün bölgelerde eğimli modele göre daha yüksek bulunmuştur (Şekil 4).

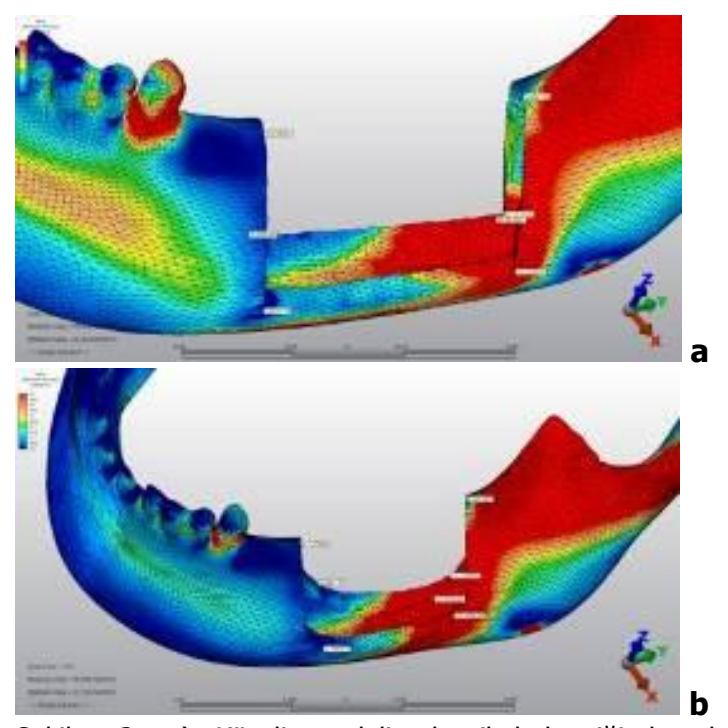

Şekil 3. a) Köşeli modelin kortikal kemiğinde oluşan maksimum principal stres değerlerinin dağılımı. b) Eğimli modelin kortikal kemiğinde oluşan maksimum principal stres değerlerinin dağılımı
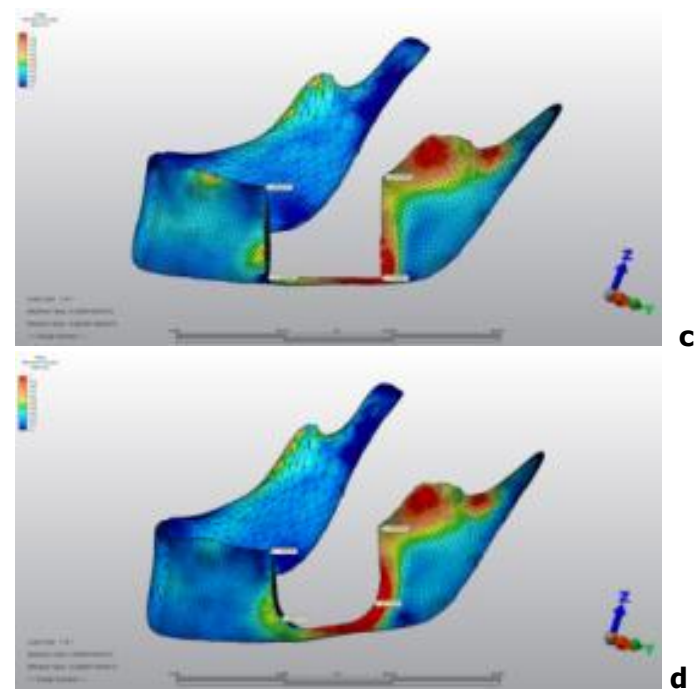

Şekil 3. c) Köşeli modelin spongioz kemiğinde oluşan maksimum principal stres değerlerinin dağıııı . d) Eğimli modelin spongioz kemiğinde oluşan maksimum principal stres değerlerinin dağııımı

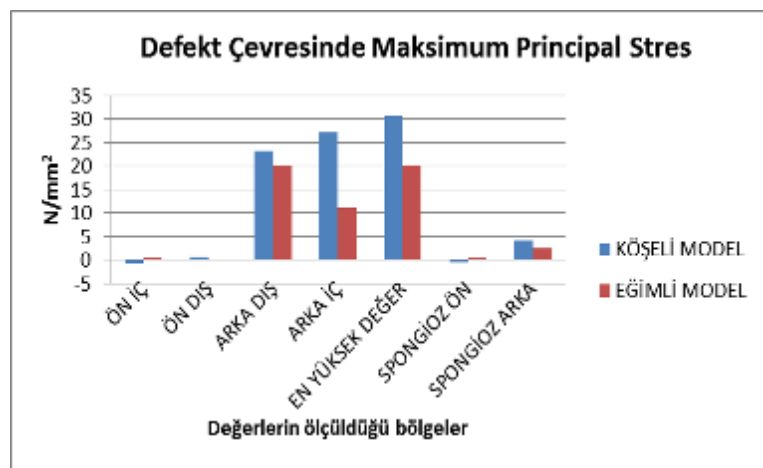

Şekil 4. Köşeli ve eğimli modellerde meydana gelen maksimum principal stres değerlerinin karşılaştırıması

Köşeli ve eğimli modellerin minimum principal stres değerleri karşılaştırıldığında (Şekil 5); bütün bölgelerde köşeli modelde daha fazla stres biriktiği, ayrıca her iki modelde de defektin ön tarafındaki spongioz ve kortikal kemiklerde daha fazla stres biriktiği görülmüştür. Her iki modelde kendi içinde en yüksek değerler kortikal kemikteki ön dış köşeden alınmıştır (Şekil 6).

Modellerde meydana gelen yer değiştirme büyüklükleri değerlendirildiğinde(Şekil 7), her iki modelde de arka köşelerde (özellikle arka üst köşede) daha yüksek değerler elde edilmiştir. Modeller arasında ya pılan karşlaş̧ırmada ise köşeli modelde bütün bölgelerde daha fazla yer değiştirme gözlenmiştir (Şekil 8).

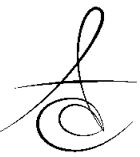



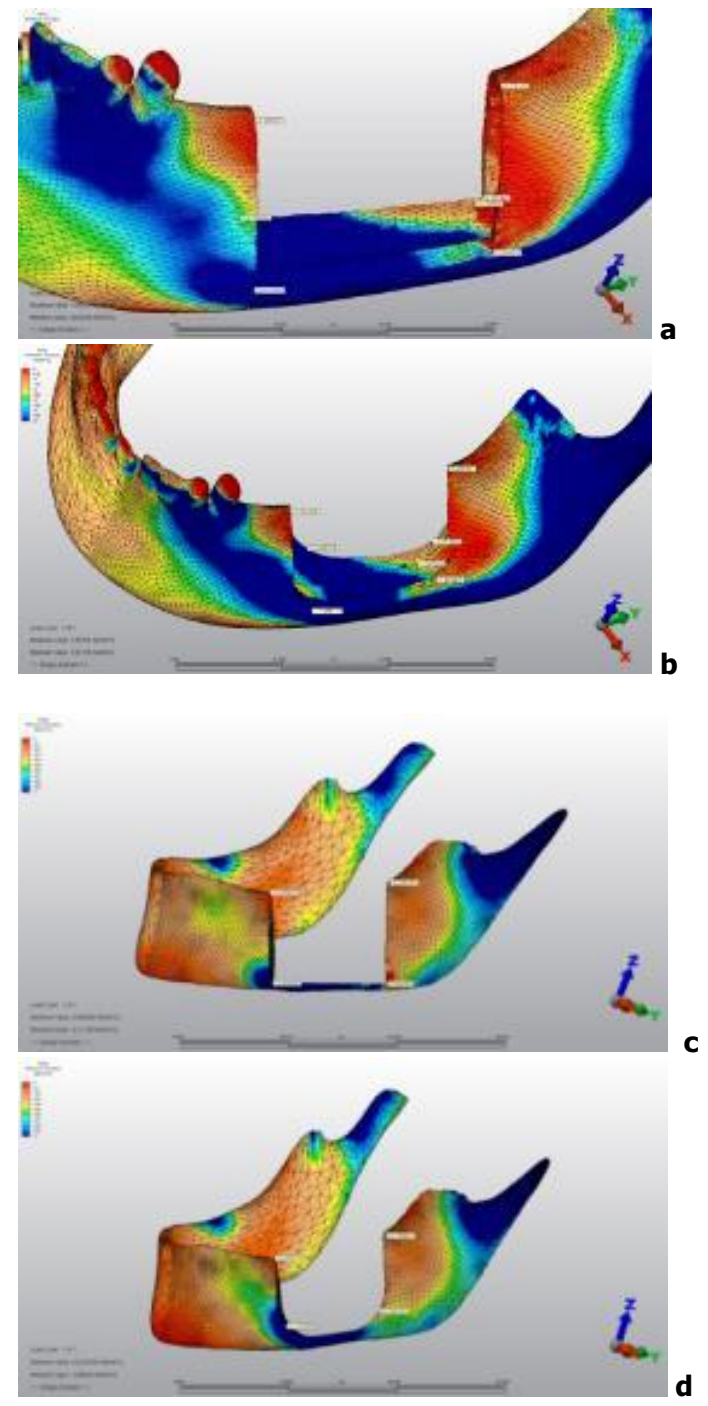

Şekil 5. a) Köşeli modelin kortikal kemiğinde oluşan minimum principal stres değerlerinin dağılımı. b) Eğimli modelin kortikal kemiğinde oluşan minimum principal stres değerlerinin dağılımı. c) Köşeli modelin spongioz kemiğinde oluşan minimum principal stres değerlerinin dağılımı. d) Eğimli modelin spongioz kemiğinde oluşan minimum principal stres değerlerinin dağııımı

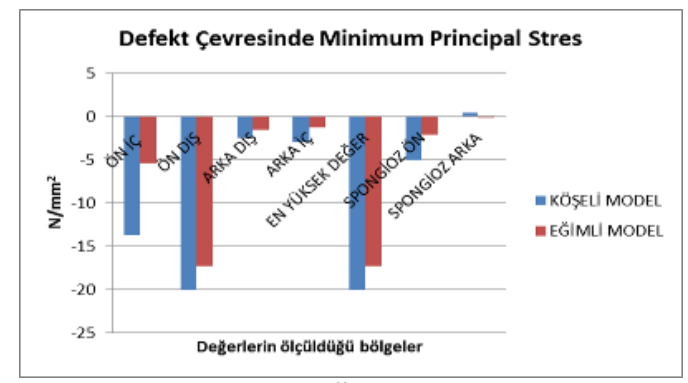

Şekil 6. Köşeli ve eğimli modellerde meydana gelen minimum principal stres değerlerinin karşılaştırıması
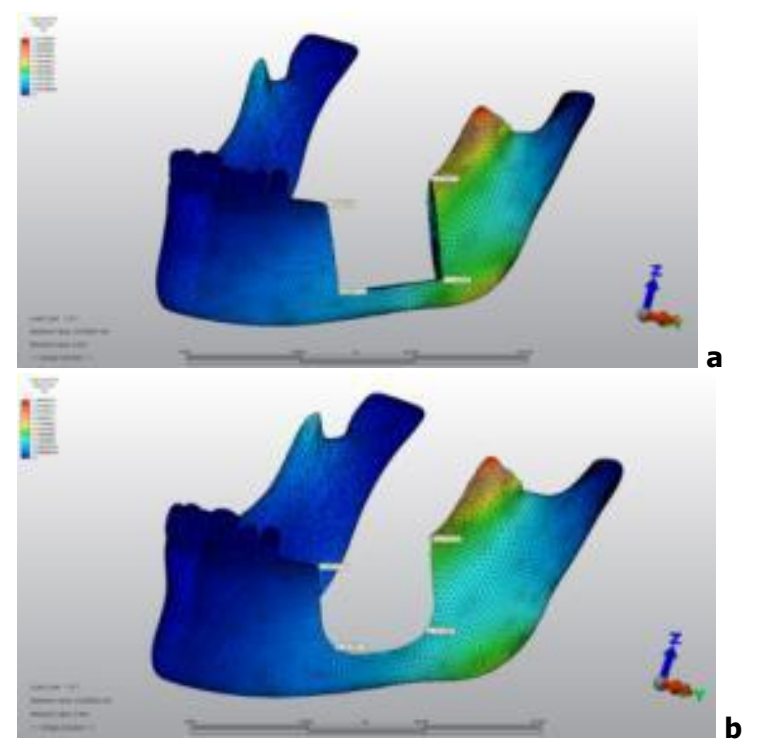

Şekil 7. a) Köşeli modelde meydana gelen yer değiştirme büyüklüklerinin dağılımı. b) Eğimli modelde meydana gelen yer değiştirme büyüklüklerinin dağılımı

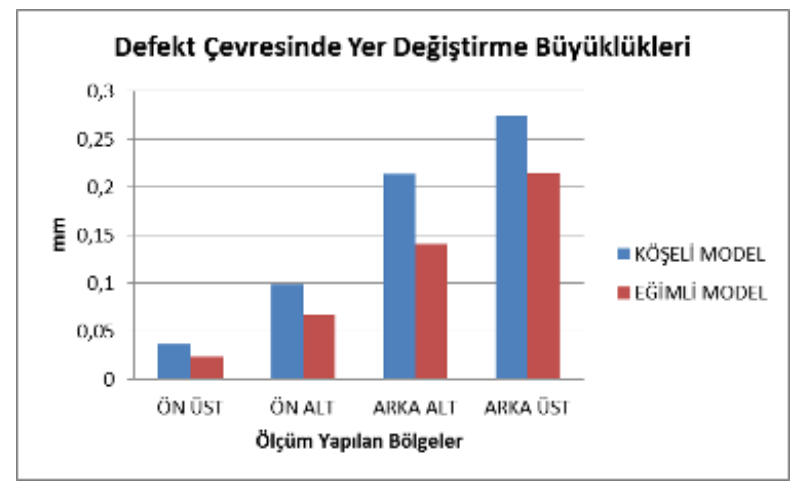

Şekil 8. Köşeli ve eğimli modellerde meydana gelen yer değiştrme büyüklüklerinin karşılaştırılması

\section{TARTIŞMA}

Ağız tabanındaki veya mandibulayla ilişkili malign lezyonların eksizyonunda önceleri marjinal mandibulektomiye şüpheyle bakılmış ve segmental rezeksiyon tercih edilegelmiştir. Ancak son yıllarda yapılan birçok çalışmada seçilmiş vakalarda marjinal mandibulektominin de güvenle uygulanabileceği ve postoperatif nüks oluşma yönüyle segmental mandibulektomi ile aralarında anlamlı bir fark bulunmadığı belirtilmiştir. ${ }^{12,13} \mathrm{Bu}$ durum marjinal mandibulektominin tercih edilmesinde artışa neden olmuştur. Çünkü

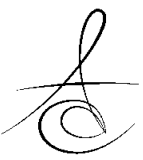


marjinal mandibulektomi, postoperatif süreçte önemli avantajlar sağlamaktadır. Daha önce bahsettiğimiz bu avantajların yanında yöntem, postoperatif dönemde mandibulada kırık oluşma riskini de beraberinde getirmektedir. Çalışmamız, farklı rezeksiyon tasarımlarını sonlu eleman analizi yöntemiyle karşılaştırarak bu önemli riski ortadan kaldırma veya azaltma amacını taşımıştır.

"Sonlu eleman analizi, karmaşık geometriye sahip yapılarda meydana gelen gerilme stresi, sıkışma stresi ve yer değistirmelerin hassas bir sekilde incelenmesine olanak sağlayan matematiksel bir yöntemdir. Yöntem, analizi yapılacak yapıların, asıllarına en yakın şekilde modellenmesi ve yapıların fiziksel özelliklerinin oluşturulan modellere yansıtılması ile oluşan stres değerlerinin gerçeğe en yakın şekilde hesaplanmasına olanak sağlamaktadır".5,14 Modellemenin gerçeğe en yakın şekilde yapılmasının yanında sınır koşullarının doğru şekilde ve amaca hizmet edecek şekilde belirlenmesi çok önemlidir. Çalışmamızda da üç boyutlu modelleme ve materyal özelliklerinin doğru yansıtılmasında gereken hassasiyet gösterilmiş, çeneye uygulanan kas kuvvetlerinin büyüklükleri ve doğrultuları literatür ışığında belirlenmiştir. ${ }^{7-11}$ Sınır koşulları belirlenirken ise çeneyi kapatan kasların aktif olduğu ısırma anı simüle edilmeye çalışılmış, bunun için kondil sadece $X$ ekseni çevresinde rotasyona izin verecek şekilde diğer yönlerde sabitlenmiş ve yine dişler kronlarının üzerinden tam ısırma anını yansıtmak için sabitlenmiştir.

Analizler yorumlanırken hangi bölgelerden ölçüm alınacağı ve nerelerde hangi stres tipinin önem arz ettiği iyi bilinmelidir. Bu hem gereksiz veri kalabalığı oluşmasının önüne geçmek hem de verileri doğru yorumlamak için çok önemlidir. Çalışmamızda, defektin postero-inferior ve antero-inferior bölgelerinin dış kortikal, spongioz ve iç kortikal kemikler üzerindeki köşelerinden örnek ölçümler yapılmış ve defekt tabanında oluşan en yüksek stresler de kaydedilmiştir. Bahsi geçen bölgelerden yapılan ölçümlerde kemik gibi kırılgan yapılarda önem arzeden principal stresler dikkatle ele alınmış ve genel bir fikir vermesi açısından Von Mises stresler de değerlendirilmiştir. Mandibulanın kuvvetler karşısında zayıf bölgelerden ne kadar esnediği konusunda fikir veren yer değiştirme büyüklükleri ise defekt çevresindeki dört ayrı köşeden ölçülmüştür.

Melugin ve ark. ${ }^{15}$ yaptıkları bir invitro çalışmada köşeli ve eğimli marjinal rezeksiyon uyguladıkları man- dibulaların okluzal kuvvetler altında defektin posteroinferior köşesinden kırıldıklarını gözlemlemişlerdir.

Wax ${ }^{16}$ rezeksiyonun kenarlarının ve özellikle köşelerinin keskinlik kalmayacak şekilde traşlanmasının iyileşmeyi kolaylaştıracak ve stres yoğunlaşmasını azaltacak bir faktör olduğunu belirtmektedir.

Barttelbort ve ark. ${ }^{17}$ mandibulektominin köşeli olarak hazırlanması sebebiyle gelişen \% 15 kırık insidansı bildirmiştir.

Ertem $^{5}$ köşeli ve eğimli yapılan marginal mandibulektomileri karşılaştırmış ve köşeli tasarımda özellikle posterior köşede ve dış kortekste daha fazla stres oluştuğunu belirtmiştir. Bizim çalışmamızda ise her iki modelde de iç korteksin postero-inferior köşesine yakın kısımlarında en yüksek stresler alınmıştır. Bu farkılığın, bahsi geçen çalışmada sınır şartları, yükleme koşulları, rezeksiyonun lokalizasyon ve şeklindeki farklılıklar sebebiyle meydana geldiği düşünülmektedir.

Çalışmamızda köşeli ve eğimli tasarıma sahip marjinal mandibulektomi modelleri ısırma kuvvetleri altında değerlendirilmiş köşeli tasarıma sahip modelde, oluşturulan defekt çevresinde daha fazla stres biriktiği görülmüştür. Her iki modelde de stresler en fazla defekt tabanının arka kısımlarında toplanmıştır. Ayrıca kuvvetlerin etkisiyle köşeli modelde eğimli modele göre daha fazla yer değiştirme izlenmiş, buradan da köşeli modelin zayıf kısımlarından eğimli modele göre daha fazla esnediği çıkarımı yapılmıştır. Bu veriler ışı̆ında köşeli modelin ısırma kuvvetleri karşısında kırılmaya daha yatkın olduğu düşünülmektedir. Bu açıdan elde ettiğimiz sonuçlar yukarıda bahsedilen çalışmalarla uyumluluk arzetmektedir.

\section{SONUÇ VE ÖNERÍLER}

Çalışmamızda karşılaştırılan köşeli ve eğimli tasarımla yapılan marjinal mandibulektomilerden köşeli olanın belirgin dezavantajlar taşıdığı ve diğer modele göre daha fazla kırılma riski taşıdığı görülmüştür. Bu yüzden rutin pratikte eğimli rezeksiyon tasarımının kullanılmasının daha uygun olacağı düşünülmektedir.

Sonlu eleman analizi yöntemi avantajlarının, yanında bazı limitasyonlar da barındırmaktadır. Bu yüzden elde edilen sonuçlar klinik çalışmalarla desteklenmeye muhtaçtır.

Çalışmamızdaki modeller sadece ısırma sırasındaki kuvvetler altında değerlendirilmiştir, ancak insan mandibulası çok kompleks hareketler yapabilen

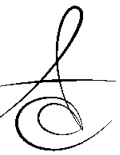


ve çok farklı yönlerden kuvvetlere maruz kalabilen bir yapıdır. Bu yüzden bizim çalıştığımız bu modellerin farklı kuvvetler altında karşılaştırıldığı yeni çalışmalar planlanabilir.

\section{KAYNAKLAR}

1. Namaki $S$, Matsumoto $M$, Ohba $H$, et al: Masticatory efficiency before and after surgery in oral cancer patients. Comparative study of glossectomy, marginal mandibulectomy and segmental mandibulectomy. J. Oral Scie 2004; 46:113-7

2. Haraguchi M., Mukohyama. H, Reisberg D. J., Tanıguchı $H$. Electromyographic activity of masticatory muscles and mandibular movement during function in marginal mandibulectomy patients. J Med Dent Sci 2003; 50: 257-64

3. Cril, Gw. Carcinoma of the Jaws, Tongue, Cheek and Lips. Surg Gyn Obs 1923;36:159-62.

4. Moore Sr, Johnson Nw, Pierce Am, Wilson Df. The Epidemiology of Mouth Cancer: A Review of Global Incidence. Oral Dis 2000;6:65-74.

5. Ertem S.Y. Eğimli Ve Köşeli Yapılan Marjinal Mandibulektominin Kuvvet İletimine Etkisinin Üç Boyutlu Modelleme Ve Sonlu Elemanlar Analizi İle Değerlendirilmesi. T.C. Başkent Üniversitesi Sağlık Bilimleri Enstitüsü Ağız, Diş, Çene Hastalıkları Ve Cerrahisi Anabilim Dalı Doktora Tezi. Ankara. 2010.

6. Oğuz Y. Kilitli vida ve plak sisteminin sagittal split ramus osteotomisinde kullanılmasının üç boyutlu modelleme ve sonlu elemanlaranaliziyle incelenmesi. Doktora Tezi, Başkent Üniversitesi Sağlık Bilimleri Enstitüsü, Ağız Diş ve Çene Cerrahisi Anabilim Dalı Ankara. 2007.

7. Korioth TW, Hannam AG. Mandibular forces during simulated tooth clenching. J Orofac Pain 1994; 8: 178-89.

8. Tanaka E, Tanne K, Sakuda M. A threedimensional finite element model of the mandible including the TMJ and its application to stress analysis in the TMJ during clenching. Med Eng Phys 1994; 16: 316-22.

9. Van Eijden TM, Brugman P, Weijs Wa, Oosting J. Coactivation of jaw muscles: recruitment order and level as a function of bite force direction and magnitude. J Biomech 1990; 23: 475-85.
10. Van Eijden TM. Jaw muscle activity in relation to the direction and point of application of bite force. J Dent Res 1990; 69: 901-5.

11. Van Eijden TM. Three-dimensional analyses of human bite-force magnitude and moment. Arch Oral Biol 1991; 36: 535-9.

12. Rao LP, Shukla M, Sharma V., Pandey $M$. Mandibular conservation in oral cancer. Surgical Oncology 2012; 21: 109-18

13. Ayad T., Guertin L., Denis Soulie`Res D., Belair M., Tema, S., Nguyen-Ta^N P.F. Controversies In The Management Of Retromolar Trigone Carcinoma. Head Neck 2009; 31: 398-405

14. Tümer MK., Akbulut N, Yılmaz D, Erkmen E. Mandibulada Uygulanan Monofokal Distraksiyon Osteogenezisinin Biyomekanik Etkilerinin Sonlu Elemanlar Analizi Yöntemi İle Araştırıması. Atatürk Üniv Diş Hek Fak Derg 2013; 21: 350-5.

15. Melugin MB., Oyen OJ., Indresano AT. The Effect of Rim Mandibulectomy Configuration and Residual Segment Size on Postoperative Fracture Risk: An In Vitro Study. J Oral Maxillofac Surg 2001; 59:409-13,

16. Wax MK, Bascom DA, Myers LL. Marginal Mandibulectomy vs Segmental Mandibulectomy: Indications and Controversies. Arch Otolaryngol. 2002; 128:600-3.

17. Barttelbort SW., Bahn SL., Ariyan SA. Rim Mandibulectomy for Cancer of the Oral Cavity. Am J Surg 1987; 154:423.

\section{Yazışma Adresi:}

Dr. Dt. Recep KESTANE

Oğuzlar Mah. 1395. sk. No: 1/4

Çankaya/Ankara

e-mail: recepkestane@yahoo.com 